\title{
The role of the 'weakest link' in a pressure-driven phase transition of two polytypic polymorphs
}

Ivan Kodrin, ${ }^{a}$ Željka Soldin, ${ }^{a}$ Christer B. Aakeröy ${ }^{b}$ and Marijana Đakovic ${ }^{a *}$

${ }^{\text {a }}$ Department of Chemistry, Faculty of Science, University of Zagreb, Horvatovac 102a, HR10000 Zagreb, Croatia. *E-mail: mdjakovic@chem.pmf.hr

${ }^{\mathrm{b}}$ Department of Chemistry, Kansas State University, Manhattan, KS, 66506, USA

\section{Supplementary Information}




\section{Table of Contents}

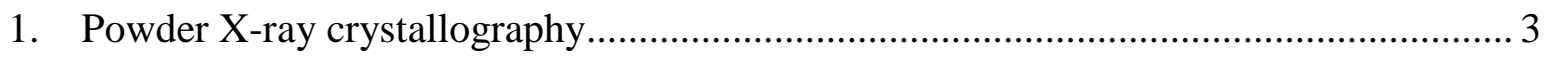

2. Single crystal X-ray crystallography ............................................................... 4

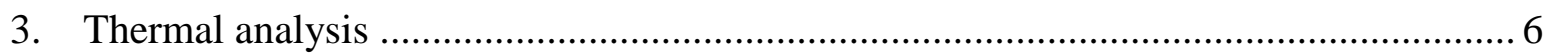

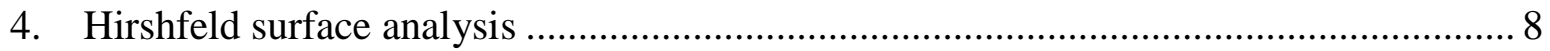

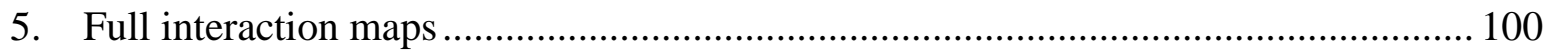




\section{Powder X-ray crystallography}

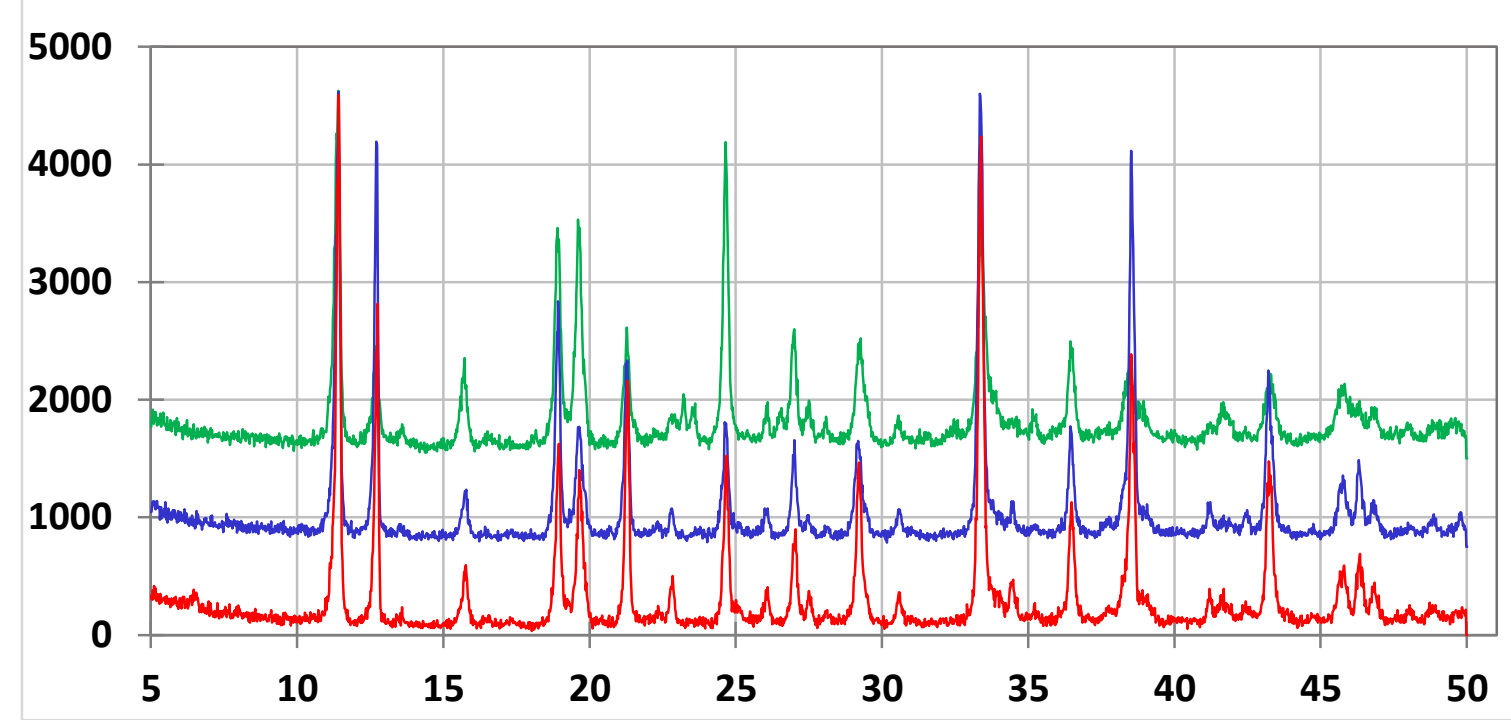

Figure S1. PXRD patterns measured for the bulk samples of Form I (blue) and Form II (red), and bulk sample obtained by solvent assisted grinding (green).

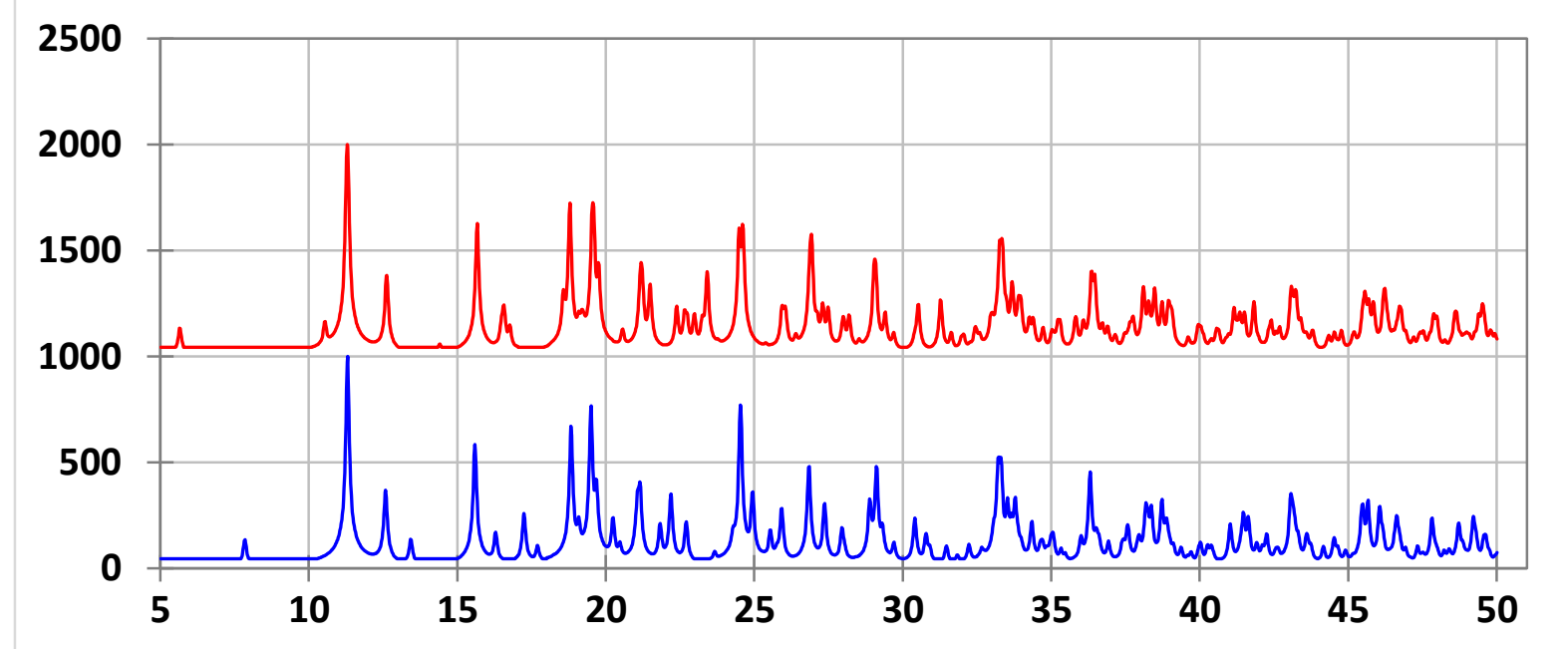

Figure S2. Simulated PXRD patterns for Form I (red) and Form II (blue). 


\section{Single crystal X-ray crystallography}

Table S1. Crystal data and details of the structure determination for $\left[\mathrm{CdI}_{2}\left(\mathrm{NH}_{2}-\mathrm{pz}\right)_{2}\right]$, Form I and Form II.

\begin{tabular}{|c|c|c|}
\hline Compounds & Form I & Form II \\
\hline Empirical formula & $\mathrm{C}_{8} \mathrm{H}_{10} \mathrm{Cd} \mathrm{I_{2 } \mathrm { N } _ { 6 }}$ & $\mathrm{C}_{8} \mathrm{H}_{10} \mathrm{Cd} \mathrm{I}_{2} \mathrm{~N}_{6}$ \\
\hline Formula weight & 556.43 & 556.43 \\
\hline Color and habit & colourless, block & yellowish, prism \\
\hline Crystal system, space group & Triclinic, $P \overline{1}$ & Monoclinic, $P 2_{1} / c$ \\
\hline Crystal dimensions / mm & $0.18 \times 0.30 \times 0.57$ & $0.14 \times 0.25 \times 0.37$ \\
\hline \multicolumn{3}{|l|}{ Unit cell parameters: } \\
\hline$a / \AA$ & $5.6587(2)$ & $5.6862(2)$ \\
\hline$b / \AA$ & $8.4757(4)$ & $18.8444(7)$ \\
\hline$c / \AA$ & $15.7805(6)$ & $14.0788(5)$ \\
\hline$\alpha 1^{\circ}$ & $97.677(3)$ & 90 \\
\hline$\beta 1^{\circ}$ & $90.768(3)$ & $92.294(3)$ \\
\hline$\gamma /{ }^{\circ}$ & $92.093(4)$ & 90 \\
\hline$V / \AA^{3}$ & $749.44(5)$ & $1507.38(9)$ \\
\hline Z & 2 & 4 \\
\hline$D_{\text {calc }} / \mathrm{g} \mathrm{cm}^{-3}$ & 2.466 & 2.452 \\
\hline$\mu / \mathrm{mm}^{-1}$ & 5.566 & 5.534 \\
\hline$\theta$ range for the data collection $/{ }^{\circ}$ & $4.39-30.00$ & $4.33-30.00$ \\
\hline$h, k, l$ range & $-7: 7,-11: 11,-22: 22$ & $-7: 7,-26: 22,-19: 17$ \\
\hline Scan type & $\omega$ & $\omega$ \\
\hline$F(000)$ & 508 & 1016 \\
\hline No. reflections collected & 7576 & 8244 \\
\hline No. independent reflections & 4336 & 4368 \\
\hline $\begin{array}{l}\text { No. observed reflections, } \\
I \geq 2 \sigma(I)\end{array}$ & 3324 & 2733 \\
\hline No. refined parameters & 171 & 170 \\
\hline$R^{a}, w R^{b}[I \geq 2 \sigma(I)]$ & $0.0272,0.0629$ & $0.0420,0.0796$ \\
\hline$R, w R$ (all data) & $0.0394,0.0662$ & $0.0753,0.0946$ \\
\hline$g_{1}, g_{2}$ in $w^{\mathrm{c}}$ & $0.0428,0.0000$ & $0.0302,0.5311$ \\
\hline Goodness of fit on $F^{2}, S^{\mathrm{d}}$ & 0.846 & 1.024 \\
\hline $\begin{array}{l}\text { Max., min. electron density / } \\
\text { e } \AA^{-3}\end{array}$ & $0.674 /-0.705$ & $1.607 /-0.760$ \\
\hline Maximum $\Delta / \sigma$ & 0.001 & 0.007 \\
\hline $\begin{array}{l}\text { Range of transmission factors } \\
\text { min, } \max \end{array}$ & $0.185,0.429$ & $0.302,0.458$ \\
\hline Extinction coefficient & $0.0046(4)$ & none \\
\hline
\end{tabular}

${ }^{\text {a }} R=\sum|| F_{o}|-| F_{c}|| / \sum\left|F_{o}\right|$.

b $w R=\left[\sum\left(F_{o}^{2}-F_{c}^{2}\right)^{2} / \sum w\left(F_{o}^{2}\right)^{2}\right]^{1 / 2}$.

${ }^{c} w=1 /\left\lfloor\sigma^{2}\left(F_{o}^{2}\right)+\left\lfloor\left(g_{1} P\right)^{2}+g_{2} P \rrbracket\right.\right.$ where $P=\left(F_{o}^{2}+2 F_{c}^{2}\right) / 3$.

d $S=\sum\left[w\left(F_{o}^{2}-F_{c}^{2}\right)^{2} /\left(N_{o b s}-N_{\text {param }}\right)\right]^{1 / 2}$. 
Table S2. Selected bond distances $(\AA)$ and angles $\left({ }^{\circ}\right)$ for $\left[\mathrm{CdI}_{2}\left(\mathrm{NH}_{2}-\mathrm{pz}\right)_{2}\right]$, Form I and Form II.

\begin{tabular}{clll}
\hline Bond distances & \multicolumn{3}{l}{ Bond angles } \\
\hline Form I & & & \\
Cd1-I1 & $2.7272(4)$ & $\mathrm{I} 1-\mathrm{Cd} 1-\mathrm{I} 2$ & $135.08(1)$ \\
$\mathrm{Cd} 1-\mathrm{I} 2$ & $2.6828(4)$ & $\mathrm{I} 1-\mathrm{Cd} 1-\mathrm{N} 1$ & $101.85(6)$ \\
$\mathrm{Cd} 1-\mathrm{N} 1$ & $2.302(3)$ & $\mathrm{I} 1-\mathrm{Cd} 1-\mathrm{N} 4$ & $102.01(6)$ \\
$\mathrm{Cd} 1-\mathrm{N} 4$ & $2.293(3)$ & $\mathrm{I} 2-\mathrm{Cd} 1-\mathrm{N} 1$ & $104.38(7)$ \\
& & $\mathrm{I} 2-\mathrm{Cd} 1-\mathrm{N} 4$ & $105.13(7)$ \\
& & $\mathrm{N} 1-\mathrm{Cd} 1-\mathrm{N} 4$ & $105.6(1)$ \\
Form II & & & \\
Cd-I1 & $2.7317(4)$ & $\mathrm{I} 1-\mathrm{Cd} 1-\mathrm{I} 2$ & $135.15(2)$ \\
$\mathrm{Cd}-\mathrm{I} 2$ & $2.6868(4)$ & $\mathrm{I} 1-\mathrm{Cd} 1-\mathrm{N} 1$ & $101.2(1)$ \\
$\mathrm{Cd}-\mathrm{N} 1$ & $2.299(4)$ & $\mathrm{I} 1-\mathrm{Cd} 1-\mathrm{N} 4$ & $102.7(1)$ \\
$\mathrm{Cd}-\mathrm{N} 4$ & $2.306(4)$ & $\mathrm{I} 2-\mathrm{Cd} 1-\mathrm{N} 1$ & $104.9(1)$ \\
& & $\mathrm{I} 2-\mathrm{Cd} 1-\mathrm{N} 4$ & $104.7(1)$ \\
& & $\mathrm{N} 1-\mathrm{Cd} 1-\mathrm{N} 4$ & $105.3(2)$ \\
\hline
\end{tabular}

Table S3. The details on hydrogen bond geometry for $\left[\mathrm{CdI}_{2}\left(\mathrm{NH}_{2}-\mathrm{pz}\right)_{2}\right]$, Form I and Form II.

\begin{tabular}{|c|c|c|c|c|c|}
\hline & $d(\mathrm{D}-\mathrm{H})$ & $d(\mathrm{H} \cdots \mathrm{A})$ & $d(\mathrm{D} \cdots \mathrm{A})$ & $\angle(\mathrm{D}-\mathrm{H} \cdots \mathrm{A})$ & $\begin{array}{l}\text { symmetry } \\
\text { operator }\end{array}$ \\
\hline \multicolumn{6}{|l|}{ Form I } \\
\hline $\mathrm{N} 3-\mathrm{H} 13 \mathrm{~N} \cdots \mathrm{N} 2$ & $0.86(3)$ & $2.19(3)$ & $3.044(5)$ & 174(3) & $3-x, 1-y,-z$ \\
\hline $\mathrm{N} 6-\mathrm{H} 16 \mathrm{~N} \cdots \mathrm{N} 5$ & $0.85(3)$ & $2.20(3)$ & $3.037(4)$ & 171(3) & $3-x,-y, 1-z$ \\
\hline $\mathrm{N} 3-\mathrm{H} 23 \mathrm{~N} \cdots \mathrm{I} 1$ & $0.86(2)$ & $3.33(4)$ & $3.678(3)$ & $106(6)$ & $2-x,-y,-z$ \\
\hline $\mathrm{N} 3-\mathrm{H} 23 \mathrm{~N} \cdots \mathrm{I} 1$ & $0.88(2)$ & $3.04(4)$ & $3.743(3)$ & $139(4)$ & $x+1, y, z$ \\
\hline 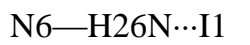 & $0.86(2)$ & $3.10(3)$ & $3.743(3)$ & $133(4)$ & $x+1, y, z$ \\
\hline $\mathrm{N} 6-\mathrm{H} 26 \mathrm{~N} \cdots \mathrm{I} 2$ & $0.86(2)$ & $3.29(4)$ & $3.678(9)$ & $110(3)$ & $x+1, y-1, z$ \\
\hline \multicolumn{6}{|l|}{ Form II } \\
\hline $\mathrm{N} 3-\mathrm{H} 13 \mathrm{~N} \cdots \mathrm{N} 5$ & $0.84(4)$ & $2.23(5)$ & $3.056(7)$ & $167(4)$ & $2-x, y-1 / 2,3 / 2-z$ \\
\hline $\mathrm{N} 6-\mathrm{H} 16 \mathrm{~N} \cdots \mathrm{N} 2$ & $0.87(4)$ & 2.17(4) & $3.034(7)$ & $171(5)$ & $2-x, 1 / 2+y, 3 / 2-z$ \\
\hline $\mathrm{N} 3-\mathrm{H} 23 \mathrm{~N} \cdots \mathrm{I} 1$ & $0.87(2)$ & $3.20(5)$ & $3.746(5)$ & $123(4)$ & $x+1, y, z$ \\
\hline $\mathrm{N} 3-\mathrm{H} 23 \mathrm{~N} \cdots \mathrm{I} 2$ & $0.87(2)$ & $3.18(5)$ & $3.689(5)$ & $119(4)$ & $x+1,1 / 2-y, z-1 / 2$ \\
\hline $\mathrm{N} 6-\mathrm{H} 26 \mathrm{~N} \cdots \mathrm{I} 1$ & $0.86(2)$ & $3.08(5)$ & $3.737(5)$ & $136(4)$ & $x+1, y, z$ \\
\hline 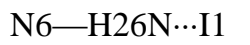 & $0.86(2)$ & $3.23(6)$ & $3.670(5)$ & $115(4)$ & $1-x, 1-y, 1-z$ \\
\hline
\end{tabular}




\section{Thermal analysis}

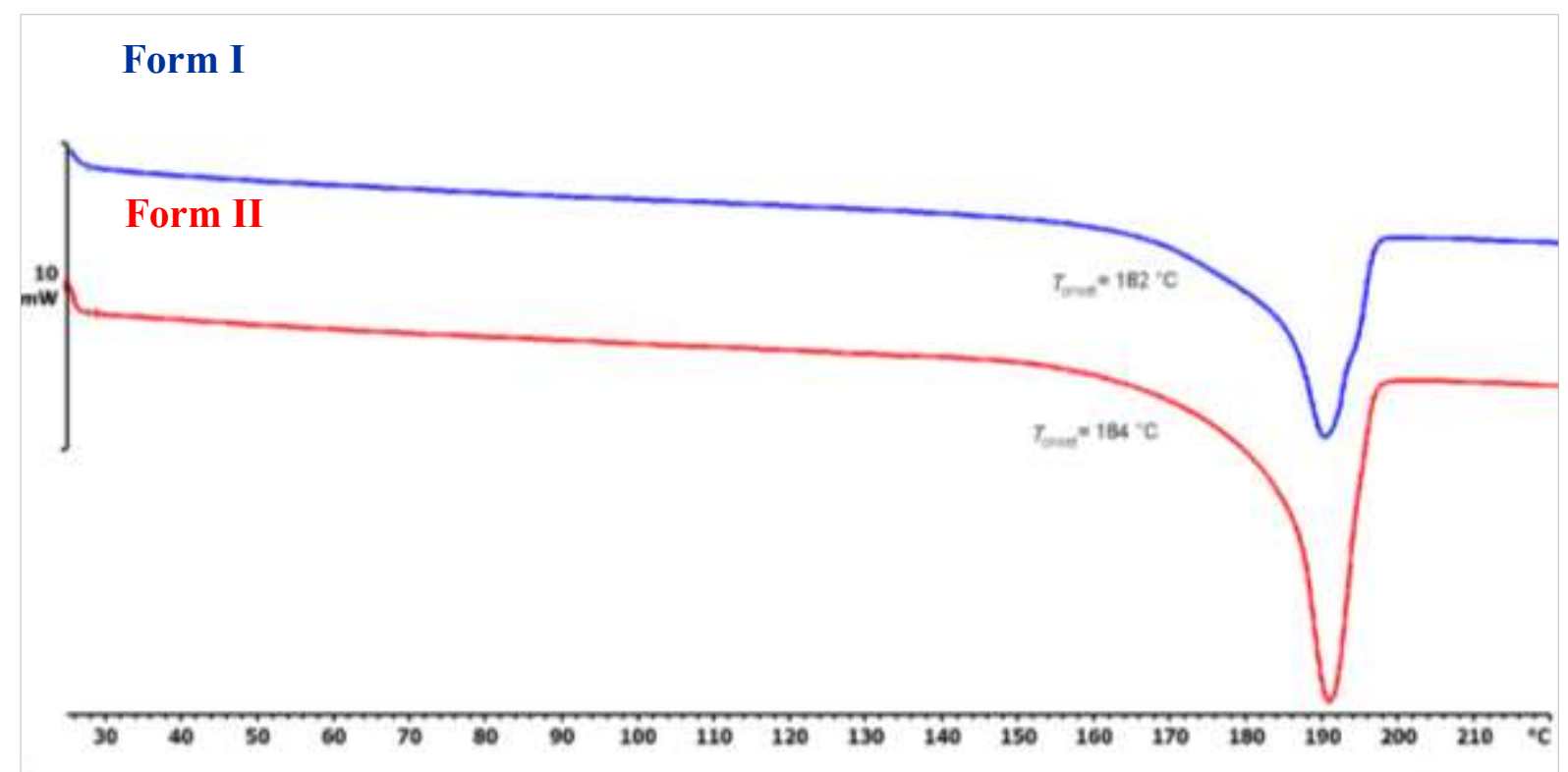

Figure S3. DSC curves for [ $\left.\mathrm{CdI}_{2}\left(\mathrm{NH}_{2}-\mathrm{pz}\right)_{2}\right]$, Form I and Form II, measured from single crystals (heating rate $10 \mathrm{~K} \mathrm{~min}^{-1}$ in flowing nitrogen).

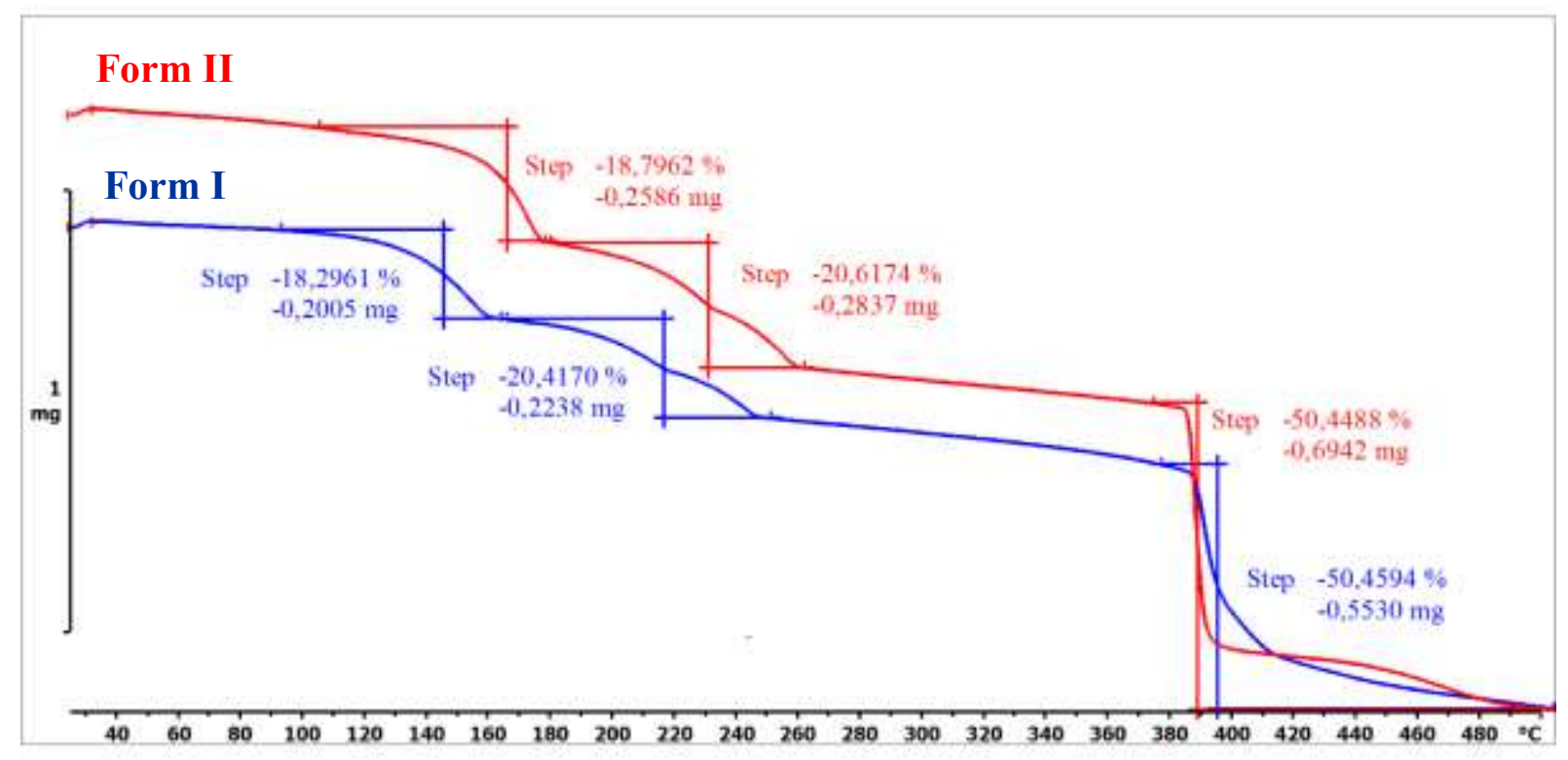

Figure S4. TG curves for $\left[\mathrm{CdI}_{2}\left(\mathrm{NH}_{2}-\mathrm{pz}\right)_{2}\right]$, Form I and Form II, measured from single crystals (heating rate $10 \mathrm{~K} \mathrm{~min}^{-1}$ in flowing nitrogen). 


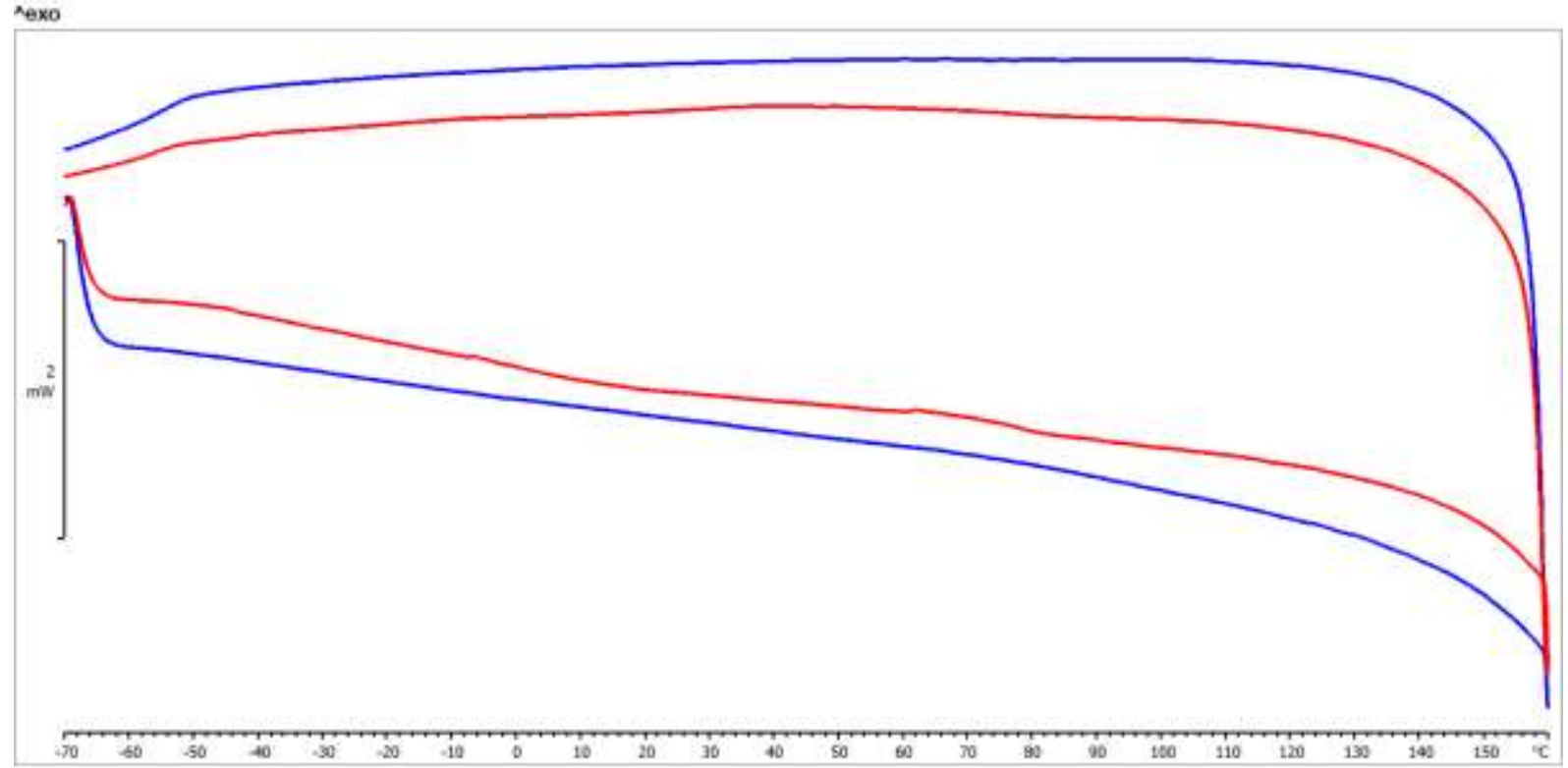

Figure S5. DSC curves for $\left[\mathrm{CdI}_{2}\left(\mathrm{NH}_{2}-\mathrm{pz}\right)_{2}\right]$, Form I (red) and Form II (blue), measured from single crystals (heating rate $10 \mathrm{~K} \mathrm{~min}^{-1}$ in flowing nitrogen). Measurements were performed starting form $-70{ }^{\circ} \mathrm{C}$ up to $+160{ }^{\circ} \mathrm{C}$ and back down to $-70{ }^{\circ} \mathrm{C}$. 


\section{Hirshfeld surface analysis}
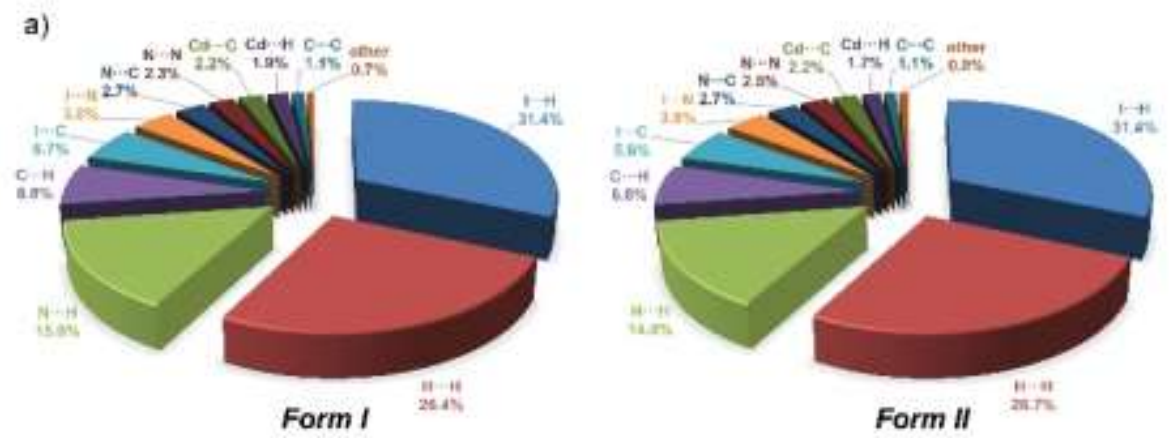

b)
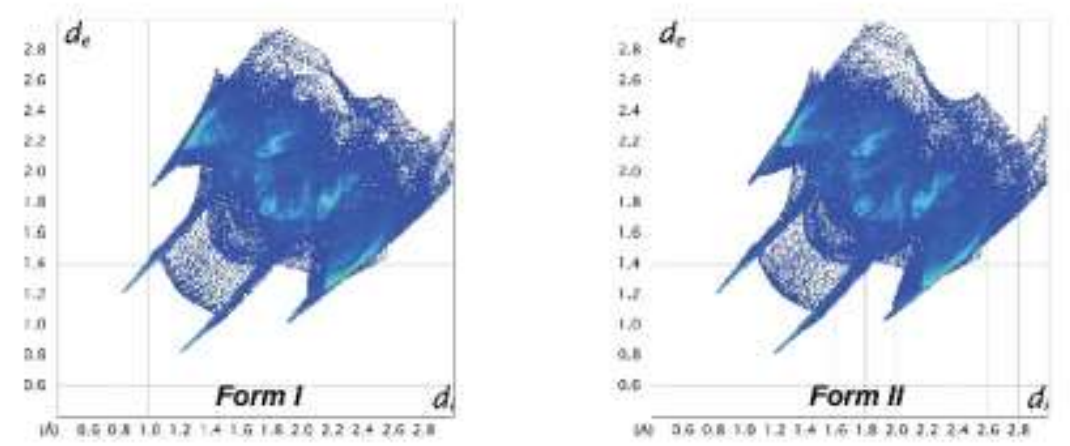

c)
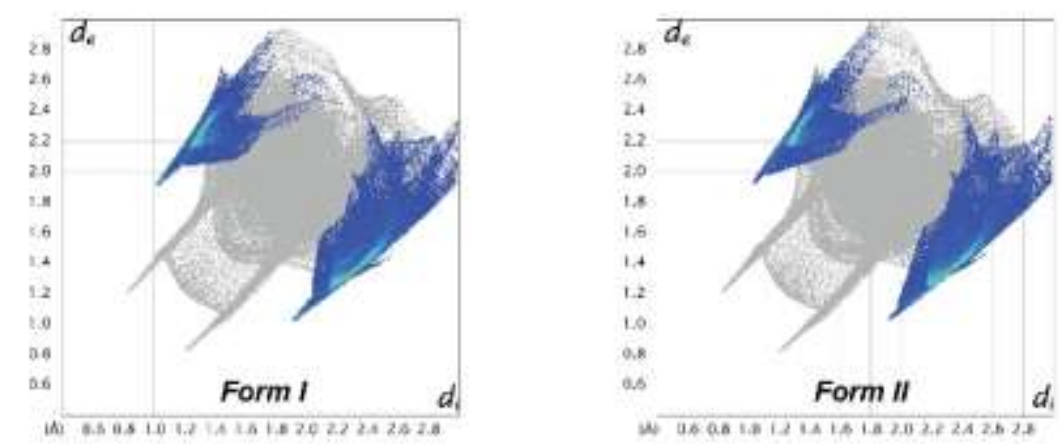

Figure S6. a) Percentage contributions of various intermolecular contacts to the Hirshfeld surface area in polymorphs I and II; b) complete fingerprints plot; c) decomposed fingerprints of the $\mathrm{N}-\mathrm{H} \cdots \mathrm{I}$ intermolecular interactions, the grey shadow is an outline of the complete fingerprint plot.

A summary of the relative contributions of different intermolecular interactions is shown in Fig. S7, and the pie-charts are almost identical. First, the structure determinations of I and II underscore the importance of the $\mathrm{N}-\mathrm{H} \cdots \mathrm{N}$ generated ribbon that connects neighboring 2aminopyrazine molecules. These interactions have almost the same relative contributions of $15.0 \%$ and $14.6 \%$ in Forms I and II, respectively, which is consistent with the observed hydrogen-bond interactions. Second, the supramolecular polymeric chains are connected into three-dimensional networks through $\mathrm{N}-\mathrm{H} \cdots \mathrm{I}$ interactions and both forms display the same percentage of $31.4 \%$. A close examination of the $2 \mathrm{D}$ fingerprint plots shows that differences in packing scheme of both polymorphs are almost insignificant. The pair of two long spikes at the 
bottom left of each plot (i.e. small $d_{\mathrm{i}}$ and $d_{\mathrm{e}}$ values in Fig. S7.b and c) represents the intermolecular $\mathrm{N}-\mathrm{H} \cdots \mathrm{N}$ hydrogen bond. Additionally, the pattern of diffuse points between these two long spikes is associated with their cyclic character. The second pair of spikes (Fig. $\mathrm{S} 7 \mathrm{~b}$ ) is due to $\mathrm{N}-\mathrm{H} \cdots \mathrm{I}$ interactions with larger values of $d_{\mathrm{i}}, d_{\mathrm{e}}$. Only the shortest $\mathrm{N}-\mathrm{H} \cdots \mathrm{I}$ interactions produce a spike and they arise from the $\mathrm{N}-\mathrm{H} \cdots \mathrm{I}$ interactions that connect $1 \mathrm{D}$ chains into 2D layers. The corresponding values are shown in Table 2. Form I has shorter $\mathrm{N}-\mathrm{H} \cdots \mathrm{I}$ distances $(2.94 \AA$ and $2.99 \AA)$ than those found in Form II (2.96 $\AA$ and $3.12 \AA$ ) (pattern B, Fig. 6). A set of longer $\mathrm{N}-\mathrm{H} \cdots \mathrm{I}$ interactions corresponds to contacts between neighboring 2D layers. This time, the $\mathrm{N} \cdots$ I distances are shorter in Form II (3.12 $\AA$ ) than in Form I (3.25 $\AA$ ) (pattern C, Fig. 6). 


\section{Full interaction maps}

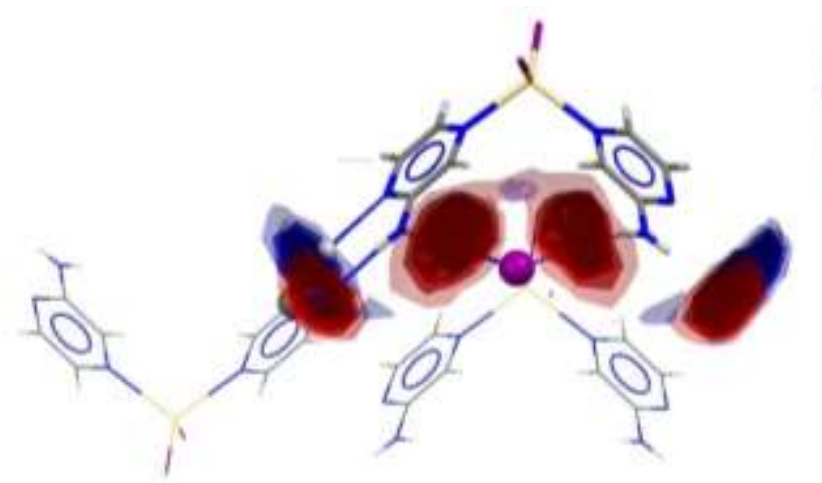

(a)

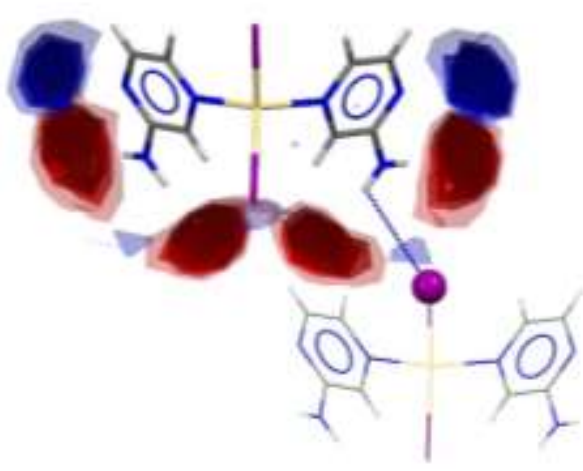

(b)

Figure S7. Interaction maps shown around the molecule of bis-(2-aminopyrazine) di-iodocadmium(II). Presented are hydrogen bonding interactions that form 2D layers (a), and stacking of 2D layers into 3D supramolecular architecture (b).

In Fig. S8 are shown the interaction maps for bis-(2-aminopyrazine) di-iodocadmium(II) molecule, and additionally interactions that are established within 2D layers (selfcomplementary $\mathrm{N}-\mathrm{H} \cdots \mathrm{N}$ and stronger $\mathrm{N}-\mathrm{H} \cdots \mathrm{I}$, Fig. S8a) and interactions that determine stacking of 2D layers (weaker $\mathrm{N}-\mathrm{H} \cdots \mathrm{I}$, Fig. S8b).

Visual analysis of the interaction maps shows that there are six well defined hotspots (the large, opaque red and blue regions) that indicate a high density and a clearly preferred geometry of six interactions. All six interactions indicated by the interaction maps are satisfied by contacts from neighboring molecules in 1D and 2D (Fig. S8a) although the quality of fit varies between those in 1D and 2D. While the interactions that determine the 1D chains (self-complementary $\mathrm{N}-\mathrm{H} \cdots \mathrm{N}$ hydrogen bonds) have acceptors and donors near the center of the strongest interaction map peaks, those that determine the $2 \mathrm{D}$ layers $(\mathrm{N}-\mathrm{H} \cdots \mathrm{I}$ hydrogen bonding interactions) have matching acceptors at the borderline of their contours. Interactions that give rise to stacking of the 2D layers do not correspond to any of the interaction regions indicated by the interaction map peaks or diffuse regions suggesting that these interactions are the least favorable ones. These results agree with energy calculated for the three hydrogen bonding interactions. 